\title{
ASSESSING NDVI SPATIAL PATTERN RELATED TO MANAGEMENT ZONES
}

\author{
LIU, H. - WANG, X. \\ Heilongjiang Bayi Agricultural University, No. 5 Xinfeng Road, Daqing High-Tech Zone, \\ Heilongjiang Province, China \\ (phone: +86-139-3694-2710; fax: +86-459-681-9210) \\ *Corresponding author \\ e-mail: ndwangxi@163.com; phone: 86-138-3696-1962; fax: +86-459-681-9210 \\ (Received $19^{\text {th }}$ Dec 2018 ; accepted $6^{\text {th }}$ Mar 2019)
}

\begin{abstract}
The NDVI of GreenSeeker has proven to be an effective tool for Management Zoning. An optimal method on the basis of NDVI was proposed to establish Management Zoning accurately in this study. First, the coefficient of variation of time series distance difference of Greenseeker and UAV NDVI was tested, it was significant to evaluate the accuracy of Greenseeker NDVI for large-areas. On this basis, optimal partition numbers and partitioning algorithm were identified according to the Silhouette Coefficient of data structure, the accuracy of estimation of agronomic parameters and the difference of agronomic parameters in each plot under different partition numbers. Results demonstrate that the difference among the points of the distance sequence is not significant $(F=0.641>0.05)$. The NDVI of Greenseeker has high reliability. When the partitioning algorithm and the number of partitions are Kmeans and four, respectively, the Silhouette Coefficient and the accuracy of estimation of agronomic parameters (plant height, nitrogen content) are higher than in other treatments. At the same time, the agronomic parameters in each plot showed the significant differences. The proposed method provides a good prospect to optimize the establishment of management zones.
\end{abstract}

Keywords: nitrogen top dressing, clustering algorithm, the number of cluster, Greenseeker, UAV

Abbreviations: NDVI: normalized difference vegetation index; GS-NDVI: NDVI was detected by Greenseeker; UAV-NDVI: NDVI was detected by UAV; Si: Silhouette Coefficient; NCE: normalized classification entropy; FPI: fuzzy performance index; FCM: fuzzy c-means algorithm; HC: hierarchical clustering; RMSSDT: root mean square standard deviation; RS: R square

\section{Introduction}

Nitrogen top dressing is a promising approach to improve yield and quality of maize in the early stages of growth (Sun et al., 2018). Site-specific application of nitrogen top dressing should lead to more efficient use and reduced the load on the environment (Zhou et al., 2018; Jin and Zhou, 2018). Management zones is a common intermediate step of moving from a uniform 'field average' management system to a site-specific crop management system (Ingerstad, 1982; Raun et al., 2002; Aavidai, 2016). The NDVI has a strong correlation with maize nitrogen content. The quest for precision in $\mathrm{N}$ management has prompted numerous recent investigations exploring the potential of NDVI by improved prediction of crop N needs (i.e., fertilizer Rate) (Rajkovich et al., 2012; Abbasi et al., 2012; Herbst et al., 2009; Cilia et al., 2014; Allen et al., 1973). Therefore, the NDVI can be regarded as a basis for management zones.

The acquisition methods of NDVI mainly include satellite remote sensing, aerial remote sensing and ground remote sensing. The spectral image sensor of satellite remote sensing and aerial remote sensing uses daylight as a light source to accurately describe the state of plant growth by NDVI and image information. However, due to the influence of cloud, atmosphere and meteorological conditions, it is difficult for them to 
meet the strict requirements of nitrogen top dressing time (Cao et al., 2012). The UAV platform can solve previous problems, and its NDVI has been proved to have high accuracy, but its recharge mileage is limited (McKinion et al., 2009; Cruppe et al., 2017; Ren et al., 2008). The active spectrum sensor of ground remote sensing contains light emitting diodes (LEDs) that emit modulated light onto the canopy (thus, the term active) and detect reflectance of the modulated light from the canopy with photodiodes. Both visible and near-infrared wavelengths are typically included. With their own light sources, these sensors are less sensitive to diurnal variations than sensors that rely on ambient sunlight (Mulla et al., 1992; Fleming et al., 2000). Operationally, these sensors can be mounted on $\mathrm{N}$ fertilizer applicators equipped with computer processing and variable rate controllers, so that sensing and fertilization are accomplished in one pass over the crop. Commercial passive spectroscopy sensors mainly include Yara N-Sensor (Yara, Dulmen, Germany), GreenSeeker (Trimble, Sunnyvale, CA., USA), CropCircle (Holland Scientific Inc., Lincoln, NE, USA), and all of the above-mentioned sensors can output NDVI.

At present, there are several approximations for the development of site-specific management zones. For example, the chemical and physical properties (nitrogen content, conductivity) of soil were used to characterize spatial variability (Gerard et al., 1997; John et al., 2007; Wang et al., 2001), including topographic maps ( $\mathrm{Fu}$ et al., 2010), direct soil sampling (Coque et al., 2006), non invasive soil sampling by electrical conductivity equipment (Colaco et al., 2017). The second approach is based on yield maps, which was established through the difference between the average of yield for many years and the current year's output. The third method is the integration of the two previous approaches and considers soil and/or relief information plus the use of yield maps (Beckie et al., 1997; Jia et al., 2004). More practical approaches have also considered farmers' knowledge in order to delineate management zone s (Yang et al., 2009). All of the above information can be performed using different algorithms, such as K-mean, fuzzy clustering analysis, hierarchical clustering, etc (Orteg and Santibáñez, 2007; Yang et al., 2016; Cai et al., 2006; Chuang et al., 2006). However, the problems, such as high labor intensity and cumbersome operation, make it difficult to obtain the approximations. At the same time, the performance evaluation method of partition method is relatively single.

It is evident that NDVI is strongly associated with plant growth and soil nutrients. In this paper, the clustering method was studied based on the large-area corn canopy NDVI by the ground remote sensing sensor Greenseeker. At the same time, the NDVI of the unified location was obtained by the remote sensing image of the UAV. This study mainly completes the following two research contents.

(1) The accuracy of NDVI of Greenseeker was verified by comparing the different of data between NDVI and UAV.

(2) The optimal of partitioning algorithm and the number of partitions was proposed to establish a reasonable management zones and describe the group differences in corn growth

\section{Materials and methods}

\section{Experiment location}

The test site was located at Zhao Guang Farm, Hei He City, Heilongjiang Province (E 126 $38^{\prime}-127^{\circ} 38^{\prime} 5^{\prime \prime}, \mathrm{N} 47^{\circ} 1^{\prime}-48^{\circ} 1^{\prime}$ ) in northeastern China. The frost-free period is 
about 120 days. The annual rainfall is $570 \mathrm{~mm}$, the annual average sunshine is more than $2,700 \mathrm{~h}$, and the soil type is mainly black soil. The Institute is located at No. 12-2, Zhao Guang Farm. The corn planting adopts a double ridge with a ridge width of $1.1 \mathrm{~m}$. The area was surrounded by a space to ensure the accuracy of GPS data acceptance. The data collection time was June 12, 2016. The yellow border shows the ground-sensing Greenseeker working area (Fig. 1). The corn variety was Demei Ya No. 3, and it is 55 days after emergence. It needs to be $\geq 10^{\circ} \mathrm{C}$ and the accumulated temperature of activity is about $2200{ }^{\circ} \mathrm{C}$. It is a common early maize variety.
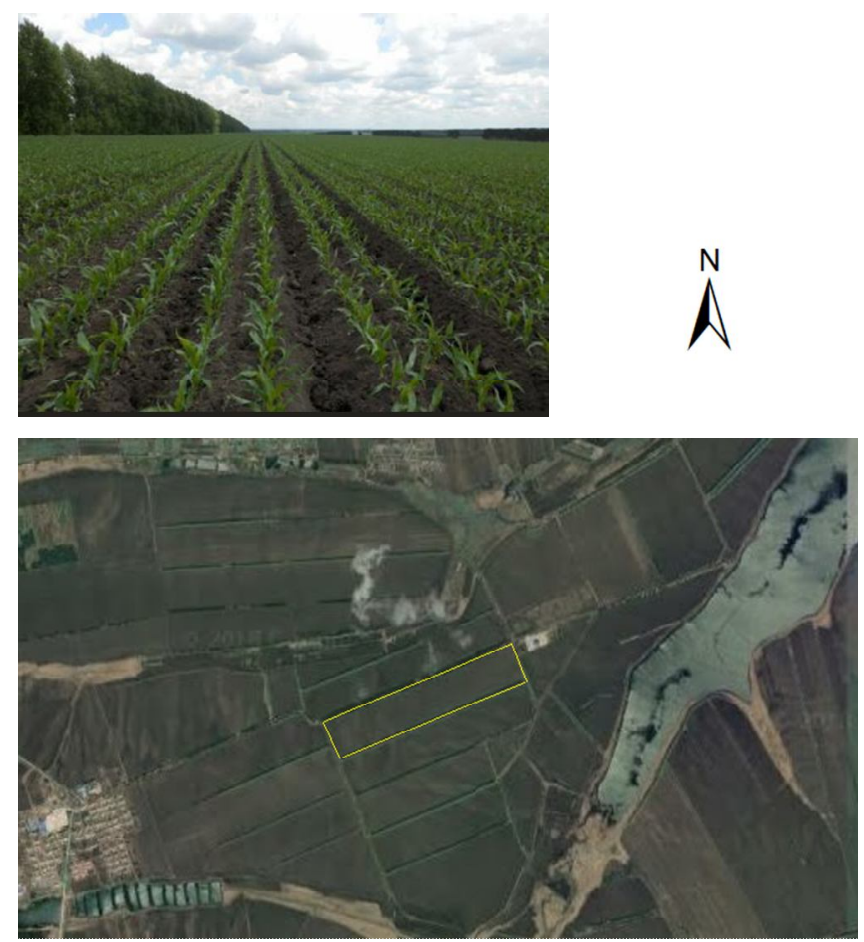

Figure 1. Sampling area

\section{Data measurement and acquisition}

The data of corn canopy was obtained by the ground remote sensing Greenseeker and the UAV remote sensing platform, respectively (Fig. 2). The ground remote sensing platform consists of six Greenseeker (Trimble, USA), Tractor (191, Valmet, Finland), Global positioning system (AG332, Trimble, USA) and VMC 1000 on-board computer (Xin Han, China). The Greenseeker was equipped with a narrow-band LED source with red light $660 \mathrm{~nm}$ and near-infrared light of $770 \mathrm{~nm}$, which can obtain NDVI of plant canopy under two bands. It has a measurement area of $61 \mathrm{~cm} \pm 10 \mathrm{~cm}$ (width) $\times 1.5 \mathrm{~cm}$ $\pm 0.5 \mathrm{~cm}$ (length). The Greenseeker vertical distance was $70 \mathrm{~cm}$ from the canopy and the detection direction was consistent with the ridge (Fig. 2a). The measurement accuracy of GPS receiver was centimeter level. The update rate of GS and GPS was $1 \mathrm{~Hz}$. The Valmet 191 tractors with manual throttle mode and speed digital display mode has the ability to work at a constant speed. According to the actual production situation, the test set the working speed to be $9 \mathrm{~km} / \mathrm{h}$ and the working area is $416000 \mathrm{~m}^{2}$. 
The UAV has a battery life of 30 minutes, and its gyroscope ensures the stability of the spectral image sensor (Fig. 2b). At the same time, the route can be planned to achieve automatic flight. The spectrum image sensor of the UAV was an agriculturalspecific multi-spectral camera (SEQUIOA, Mica Sense, USA). It has four wavelengths, Green (540-570) nm, Red (630-670) nm, Red-edge (730-750) nm and NIR (780-820) $\mathrm{nm}$, respectively. The flight height of UAV was $500 \mathrm{~m}$ and the measurement area was $39600 \mathrm{~m}^{2}$.

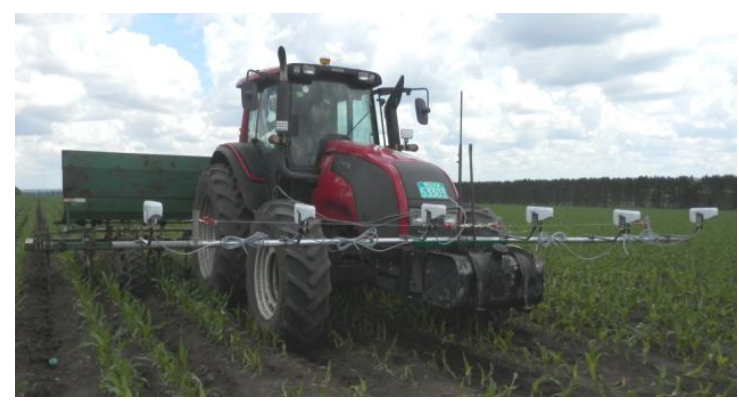

a

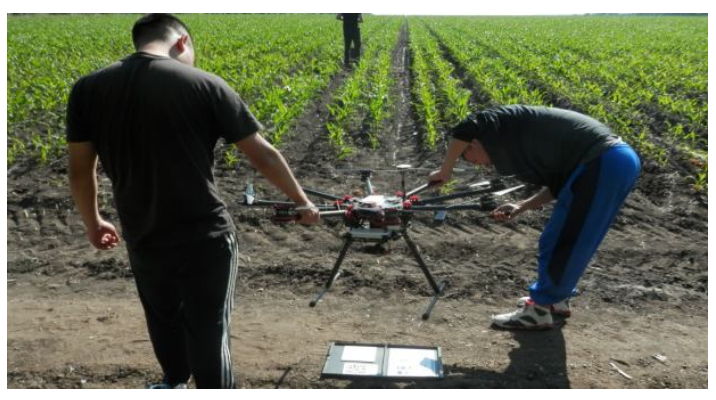

b

Figure 2. Ground remote sensing platform (a); UAV remote sensing platform (b)

\section{Spectral image processing method for $U A V$}

The spectral images have different degrees of distortion due to the imaging principle, external state and surface condition of the SEQUIOA spectral image sensor. The Agisoft Photoscan software was used to process and splicing spectral images of different channels. The spectral images were processed and spliced by Agisoft Photoscan software to obtain the orthophoto map of the four bands in the detection area, and RED and NIR images synthesized the NDVI images. In order to compare the different of NDVI between UAV and Greenseeker, the spectral image was split into a single zone using meshing methods (Fig. 3). The area of the zone was the same as that of the GS detection area. The NDVI of each zone of the spectral image was extracted and use the whiteboard to correct the coordinates of the initial zone and Greenseeker data points. Therefore, the GS-NDVI corresponds to UAV-NDVI one by one, and the difference analysis was carried out. Figure 3 is the spectral images processing flow chart.

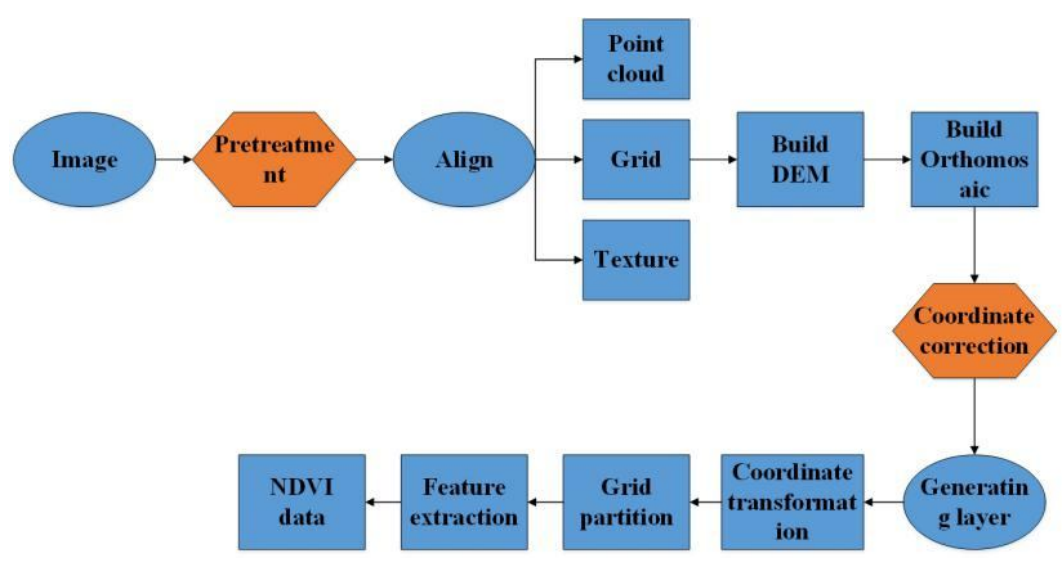

Figure 3. Spectral images processing flow chart 


\section{Partition method}

The unsupervised clustering algorithm was used to divide the MANAGEMENT ZONING of variable fertilization. The purpose of clustering was to have high similarity between objects of the same category, and highly dissimilar with objects in other clusters. This study uses the following three partition clustering algorithms.

Algorithm 1: The K-mean clustering algorithm minimizes the sum of the squares of the Euler distances from the objective function $x_{j}$ to the cluster center point $u_{i}$ based on the randomly selected cluster number and the cluster center, and the partition was generated (Zhang et al., 2010). The function was as follows:

$$
\operatorname{argmin} \sum_{\mathrm{i}=1}^{\mathrm{k}} \sum_{\mathrm{x}_{\mathrm{j}} \in C_{\mathrm{i}}}\left\|x_{j}-u_{i}\right\|^{2}
$$

The number of clusters was determined by $a i$ and $b i$ (ai: Average distance from $i$ to other samples in the same cluster; $b i$ : Average distance from $i$ to samples of different clusters). The smaller the $a i$, the more accurate classification. The smaller the $b i$, the less accurate classification (Sangalli et al., 2010). The cluster center value will collapse to its cluster data center value after the algorithm runs converged.

Algorithm 2: The fuzzy c-means algorithm obtains the membership degree of each class point to all class centers by finding the iterative minimization of the objective function, and achieves the purpose of clustering (Huang, 1998). The most commonly used objective function is:

$$
J(M C)=\sum_{k=1}^{n} \sum_{j=1}^{c} \mu_{i k} d_{i k}^{2}
$$

$C$ was the clustering category execution matrix $c \times p$. M was the sample fuzzy membership matrix $n \times c . \mu_{\mathrm{ij}}$ is the membership value of the sample attribute of the $i$-th sample to the $j$-th cluster category. $\varphi$ (fuzziness exponent) is a constant that controls the degree of overlap between clustering results and categories. $d^{2}{ }_{i j}$ is the square of the distance between the $i$-th sample attribute and the $j$-th category center. The selection of the fuzzy category number $C$ and the fuzzy weighted index $\varphi$ directly affects the output of the continuous classification. The principle of $\varphi$ selection is greater than 1 , and 1.3 is taken here (Schepers et al., 2004; Ramchandran et al., 2015; Hassan et al., 2018). The clustering number is determined by fuzzy clustering index and normalized classification entropy. The division of the cluster was evident when the value of FPI is close to 0 . NCE has similar results. The equation is as follows:

$$
\begin{gathered}
F P I=1-\frac{c}{(c-1)}\left[1-\sum_{k=1}^{n} \sum_{i=1}^{c}\left(u_{i \mathrm{k}}\right)^{2} / n\right] \\
N C E=\frac{1}{(c-1)}\left[\sum_{k=1}^{n} \sum_{i=1}^{c} u_{i k} \log _{a}\left(u_{i k}\right)\right]
\end{gathered}
$$

Algorithm 3: Hierarchical Clustering divides the nearest two samples into a family, repeating the division until there is only one family left, so there was no need to specify 
the number of classes (Di Gennaro et al., 2017). The distance between the samples can be calculated by the class average method. The order of hierarchical decomposition is in the bottom-up mode.

In order to define the optimal number of clusters, the following two indices have been used to calculate the cluster validity indicators, which are the root mean square standard deviation and the $\mathrm{R}$ square validity index (Condorelli et al., 2018). Since the purpose of clustering is to define homogeneous groups, the lower RMSSTD value in clustering analysis is better. The value ranges from $0-1$. The high value of RS indicates that there is a significant difference between the clusters, and the classification effect was better.

$$
\begin{gathered}
R M S S T D=\sqrt{\frac{\sum_{i=1}^{n_{c}} \sum_{j \in C_{i}}\left(x_{j}-\bar{x}_{i}\right)^{2}}{\sum_{i=1}^{n}\left(r_{i}-1\right)}} \\
R S=\frac{\left[\sum_{j=1}^{n}\left(x_{j}-\bar{x}\right)\right]-\left[\sum_{i=1}^{n_{c}} \sum_{j \in C_{i}}\left(x_{j}-\bar{x}\right)^{2}\right]}{\sum_{i=1}^{n}\left(x_{j}-\bar{x}\right)^{2}}
\end{gathered}
$$

$n_{c}$ was the number of clusters; $\bar{x}_{i}$ was the cluster center.

\section{Evaluation method}

\section{Difference between GS-NDVI and UAV-NDVI}

The NDVI between Greenseeker and UAV cannot be directly quantified, because the two sensors work differently, the trends were changed. Since the NDVI data is an isochronous sequence, the data only changes on the Y-axis. Therefore, the difference value of the two pairs of data was taken as a single set of random variable sample sequences. If there is no difference in the effect of the two data, the difference between each pair should be an unbiased estimator of the population mean difference. The method was T test.

\section{Performance evaluation method for different clustering algorithms}

(1) Clustering performance comprehensive evaluation parameter

The Silhouette Coefficient combines ai and bi and can be used to evaluate the impact of different algorithms or operating modes on clustering results based on the same raw data (Omran et al., 2005). It only considers dataset geometry as shown in Equation 7.

$$
s(i)=\left\{\begin{array}{l}
1-\frac{a(i)}{b(i)}, a(i)<b(i) \\
0, a(i)=b(i) \\
\frac{b(i)}{a(i)}-1, a(i)>b(i)
\end{array}\right.
$$

(2) Rationality verification of clustering method based on agronomic parameters 
According to the Site-specific fertilizer management method, a reasonable Management Zoning should have the following characteristics. The crops in the same plot have consistent growth status, and the growth status of crops between different plots have significantly different. There was a significant correlation between plant height and biomass of maize and NDVI. There the rationality of Management Zoning of NDVI was verified base on plant height and biomass of maize. The method was as follows, a multi-management partition map with location information was generated by clustering algorithms when the number of partitions is 2-6. In each plot on the map, 100 sets of sample information were collected randomly. (The height of the corn was measured by the distance of the ground to the highest stretch of all the leaves when the blade was naturally stretched. The fresh matter of the aboveground tissue was used as the corn biomass). Regression models of plant height and biomass of Maize in the same plot were established based on the total sample. The consistency of the corn growth status was evaluated by the estimated error RMSE of regression models. Based on the sample mean of plant height and biomass in each plot, comparing the differences in plant height and biomass between the various plots, and evaluating whether the corn growth status between the plots was significantly different. Through the analysis of corn agronomic parameters, the optimal clustering method was proposed to establish a reasonable management partition.

\section{Results}

\section{Comparative analysis of differences between $U A V-N D V I$ and GS-NDVI}

A significant difference can be clearly seen between soil reflectance (1 in Fig. 4) and maize reflectance (2 in Fig. 4), and the resolution is relatively high, which shows that the NDVI based on UAV has high accuracy. Red part in Figure $4 a$ stands for UAU's working area and the blue part shows the meshing. Based on the whiteboard (3 in Fig. 4). UAV mesh and GS mesh are in one-to-one correspondence (4 in Fig. 4).

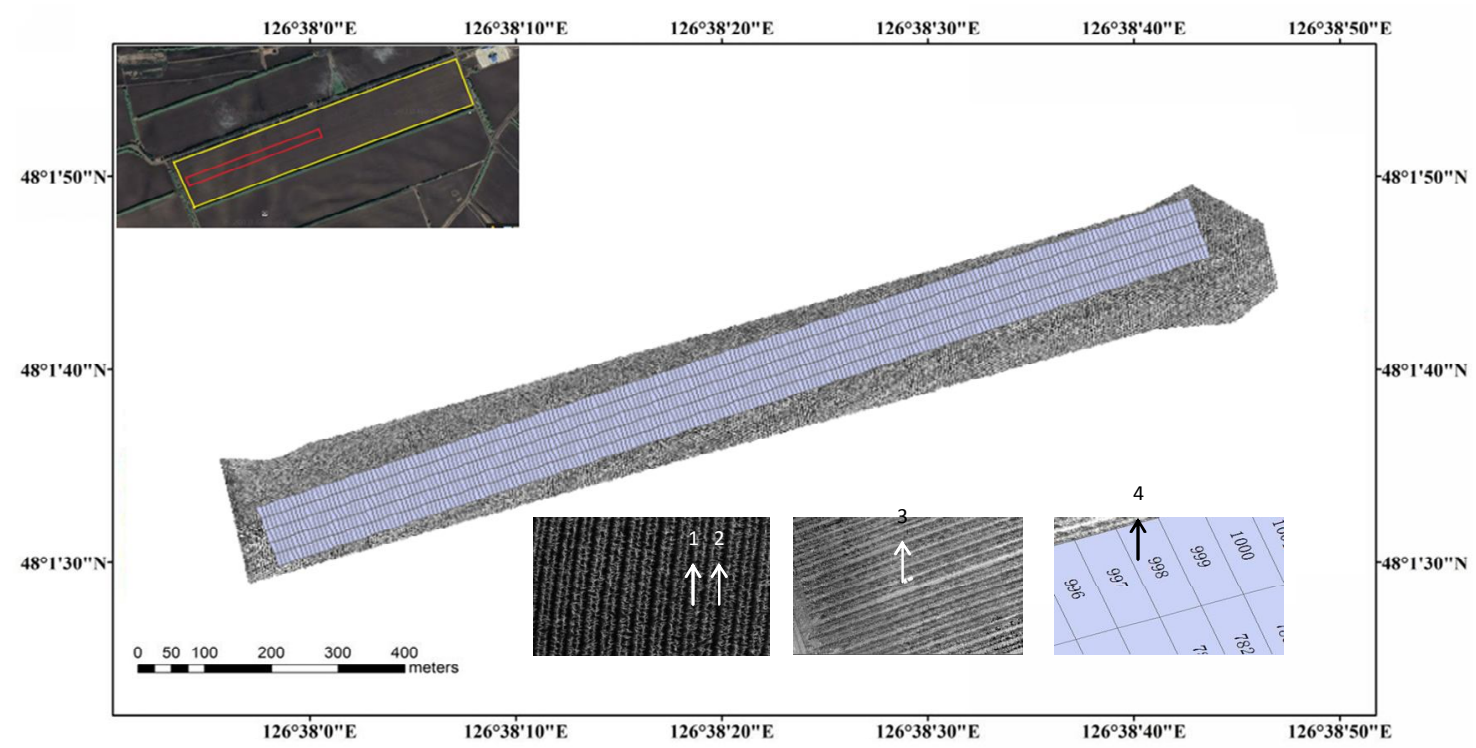

Figure 4. The image of NIR 
Figure $5 a$ shows the NDVI time series. GS-NDVI was significantly higher than UAV-NDVI, because the detection of GS is closer to the object than the UAV, and the scattering and refraction of light have less effect on GS-NDVI. The Sig $>0.05$ of the two sets of data was tested by K-S, indicating that the array belongs to a normal distribution and satisfies the preconditions of the T test (Fig. 5b and c). Univariate Ttests were performed on the arrays. The results showed that the single factor variation was not significant $(\mathrm{Sig}>0.05)$ (Table 1$)$, indicating that GS-NDVI and UAV-NDVI had similar trends throughout the time series.

\section{Performance comparison of clustering algorithms}

The GS-NDVI of detection area was described (Table 2). The variation was 17.8\%, which satisfies the preconditions for the precise agricultural division and implementation of MANAGEMENT ZONING.

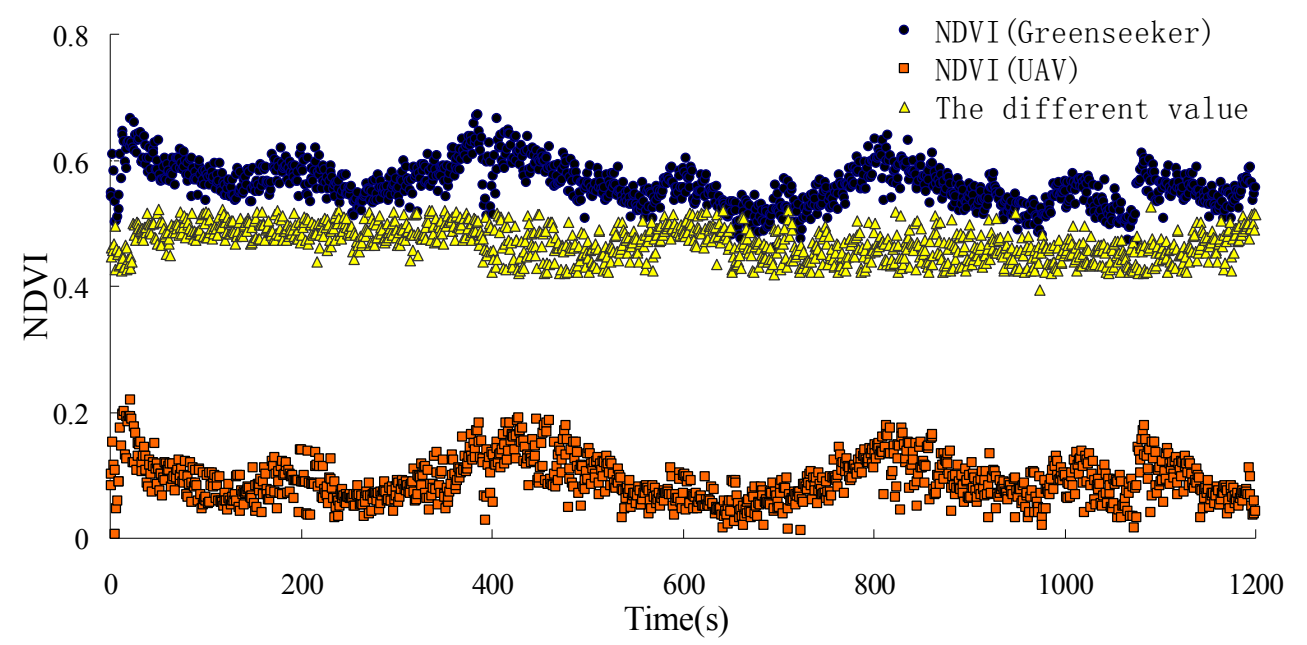

a

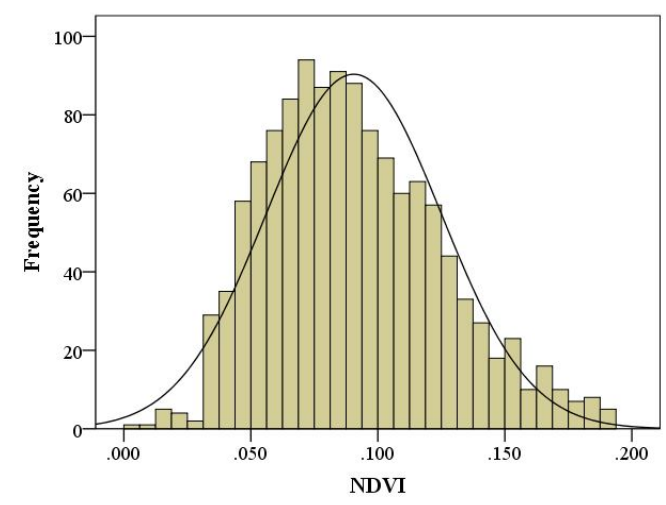

b

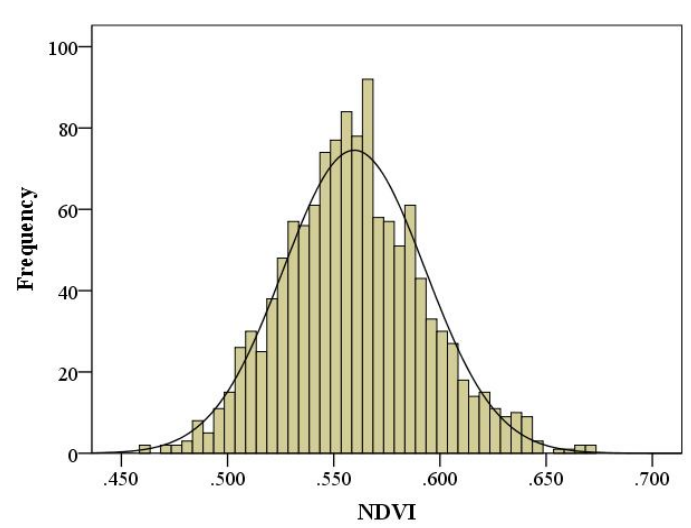

C

Figure 5. The NDVI trend with time (a); frequency distribution map of GS-NDVI (b); frequency distribution map of $U A V-N D V I$ (c)

Table 1. Statistical analysis table

\begin{tabular}{c|c|c|c|c}
\hline Sequence & Number of data & Mean & Standard deviation & Sig \\
\hline Difference value & 1249 & .46834 & .025884 & 0.848 \\
\hline
\end{tabular}


Table 2. Descriptive statistics of the sample area

\begin{tabular}{c|c|c|c|c|c|c}
\hline Data & $\begin{array}{c}\text { Number of } \\
\text { data }\end{array}$ & $\begin{array}{c}\text { Maximum } \\
\text { value }\end{array}$ & $\begin{array}{c}\text { Minimum } \\
\text { value }\end{array}$ & $\begin{array}{c}\text { Standard } \\
\text { deviation }\end{array}$ & $\begin{array}{c}\text { Variability } \\
\text { (\%) }\end{array}$ & $\begin{array}{c}\text { Time } \\
\text { consumed (h) }\end{array}$ \\
\hline GS-NDVI & 27153 & 0.84 & 0.108 & 0.089 & 17.8 & 7.62 \\
\hline
\end{tabular}

\section{The effect of clustering number and clustering method on partitioning results}

The initial cluster number was set to 2-6 and the cluster center was randomly selected. When K-mean algorithm was applied, the bi begins to increase, but then again decreased with the increase in a number of clusters, the maximum value was reached when the number of clusters was 4 . The change of ai under different cluster numbers was gentle. Therefore, when the number of clusters was 4 , the K-mean clustering has a better effect (Fig. 6a). PFI and NCE reached a minimum when the number of clusters was 3, so the FCM optimal cluster number was 3 (Fig. 6b). In RMSSTD and RS, we searched the map for the critical "knee" to find out that the optimal cluster number was 3 of Hierarchical Clustering (Fig. 6c). According to the optimal number of clusters, the $a i$ and $b i$ of each clustering algorithm was calculated. Then the $S i$ was explained by Formula 8. The results were shown in (Table 3), the $a i$ and bi of FCM was the minimum values, it indicates the data in the cell was compact and the cell division was reasonable. However, the difference between each cell in the whole region was small, resulting in lower Si. The FCM clustering algorithm could not clearly describe the overall trend of NDVI, and management zone could not be accurately established. Due to the difference in the number of partitions between $\mathrm{K}$-mean and $\mathrm{HC}$, there was a difference between $a i$ and $b i$, but $S i$ were basically the same and significantly higher than FCM. Both K-mean and $\mathrm{HC}$ have excellent ability to create management zone. Although K-mean and $\mathrm{HC}$ have similar performance, but the calculation time of $\mathrm{HC}$ was significantly longer than that of K-mean.

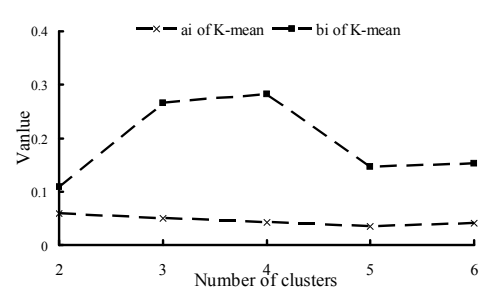

a

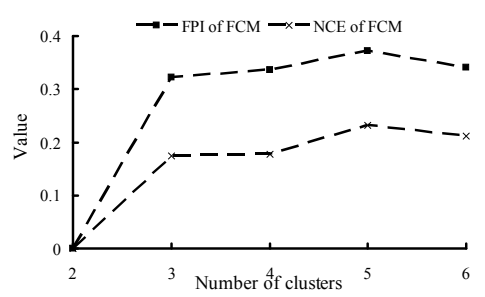

b

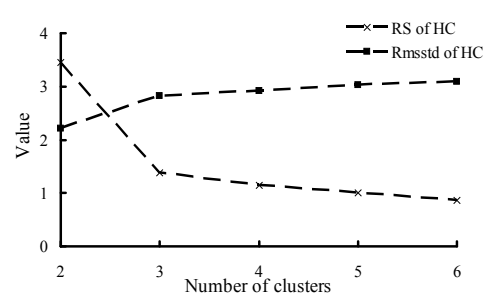

C

Figure 6. The ai and bi under different clustering numbers of K-mean (a); the FPI and NCE under different clustering numbers of FCM (b); the RMSSTD and RS under different clustering numbers of $H C(c)$

Table 3. Comparison of different clustering algorithm results

\begin{tabular}{c|c|c|c|c}
\hline Cluster & Number of partitions & $\boldsymbol{a i}$ & $\boldsymbol{b i}$ & $\boldsymbol{S i}$ \\
\hline FCM & 3 & 0.0356 & 0.169 & 0.427 \\
K-mean & 4 & 0.0399 & 0.299 & 0.817 \\
HC & 3 & 0.0439 & 0.323 & 0.811 \\
\hline
\end{tabular}


The variation trend of RMSE of plant height under different treatments was shown in Figure 7a. With the increase of the number of clusters, the RMSE trend of each clustering algorithm were gentle. The RMSE of K-mean was significantly smaller than that of HC and FCM. Therefore, clustering method was more important than clustering number in estimating maize plant height. K-means performance was stronger. When using biomass data, the RMSE of each algorithm show a trend of decreasing first and then increasing with the increase of clustering number (Fig. 7b). The RMSE have the minimum value when the cluster number was 4 , which indicates that the number of clusters was more important than the clustering algorithm in the estimation of biomass.

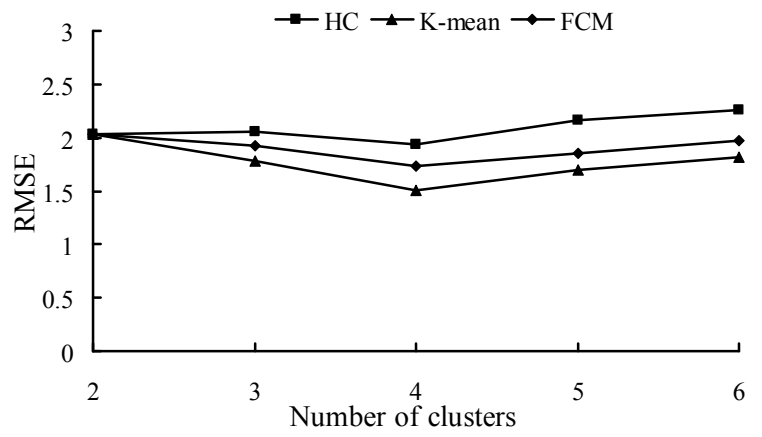

a

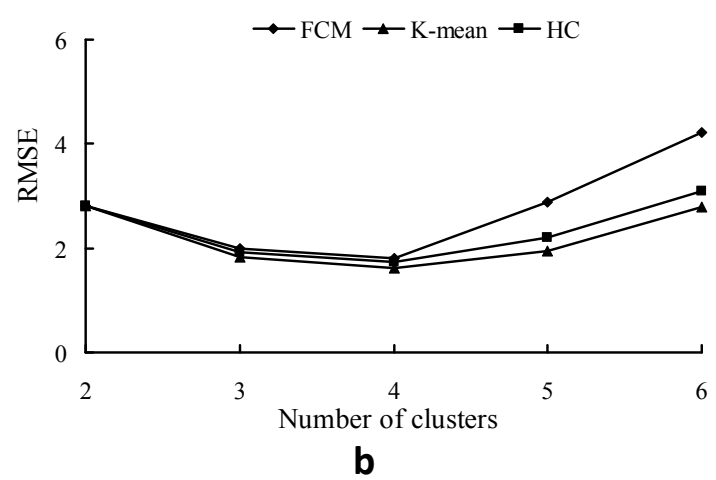

b

Figure 7. Plant height and biomass estimation error of different algorithms under different cluster numbers

The differences of plant height and fresh matter weight in different plots were shown under different clustering methods and cluster numbers (Fig. 8). The performance of each algorithm is basically the same when the partition number are 2 and 3 , respectively. When using K-mean for partitioning, the results showed that there was a significant difference in plant height and biomass between each plot when the number of clusters was 4 . As the number of partitions increases further, several plots with similar growth status of corn appeared (Same Letter), there were no significant differences in the plant height and the weight of fresh matter between them. The optimal result was still 4 partitions (Fig. 8a). HC was similar to K-mean results (Fig. 8b), but its computational complexity is significantly higher than K-mean. When using Fcm for partitioning, the partition result was similar to K-mean when the number of clusters was 6. But the SD of each plot was higher than K-mean, this indicates that the difference in corn growth in each cell of FCM has a large impact on the accuracy of the partition (Fig. 8c). In summary, four partitions can accurately express the population differences of corn growth status when use the K-mean.

Regression analysis of plant height and biomass was conducted by GS-NDVI. The $\mathrm{R}^{2}$ of fitting curves of plant height and biomass were 0.8655 and 0.9002 , respectively (Fig. 9). It shows that NDVI prediction is effective. It can be seen from the trend of the curve that the slope of the curve does not change significantly when NDVI is in the range of $0.118-0.246$ and $0.658-0.792$, respectively. The NDVI value with high or low cannot accurately predict corn plant height and fresh matter weight at this time. 

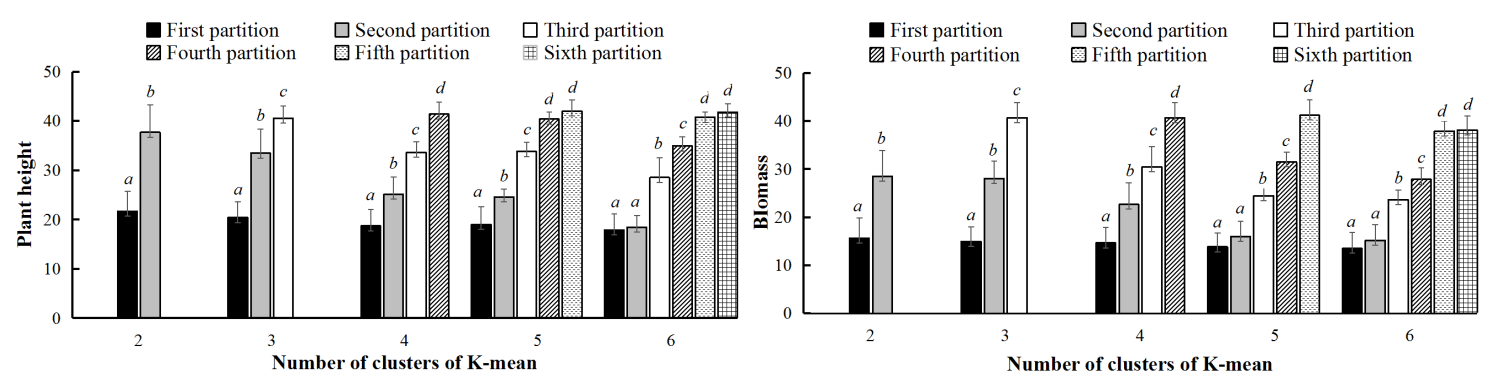

a
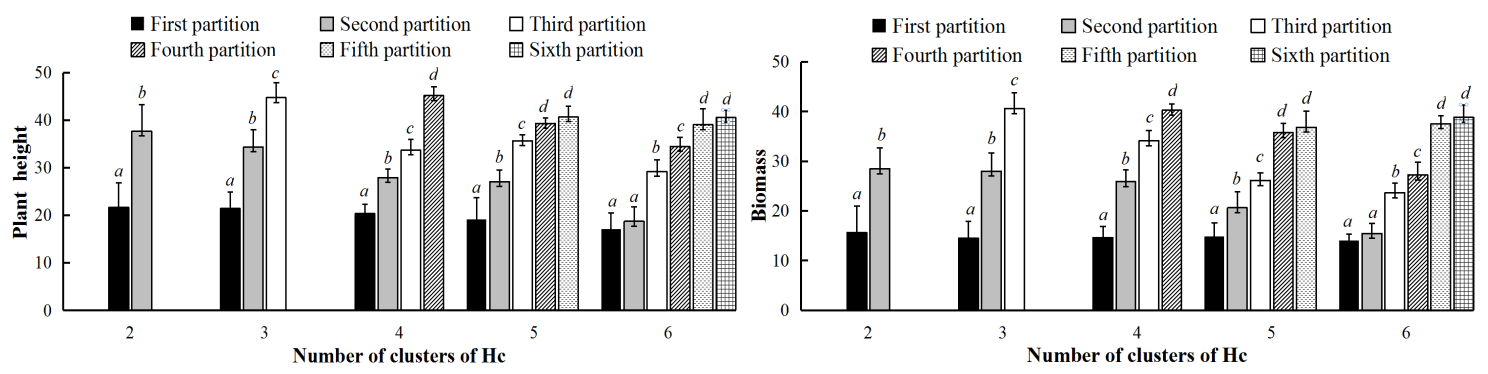

b
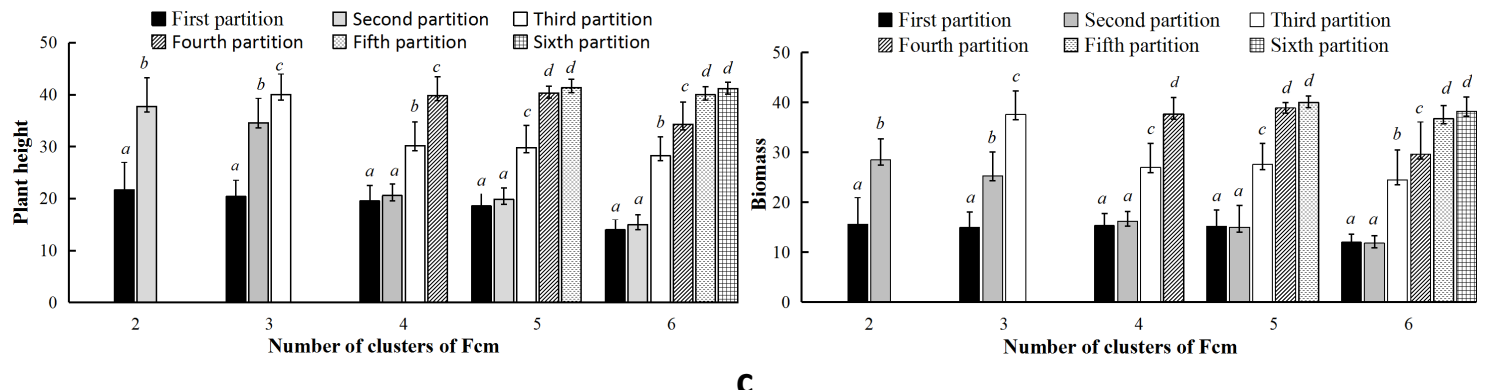

Figure 8. The difference in plant height and biomass of each plot under different cluster numbers; K-mean (a); Hc (b); Fcm (c). Marking the same letter (such as a and ab) means that the difference is not significant, and different letters (such as a and b) are significant differences. The lower-case letters $(a, b, c)$ indicate a significant level of $f=0.05$
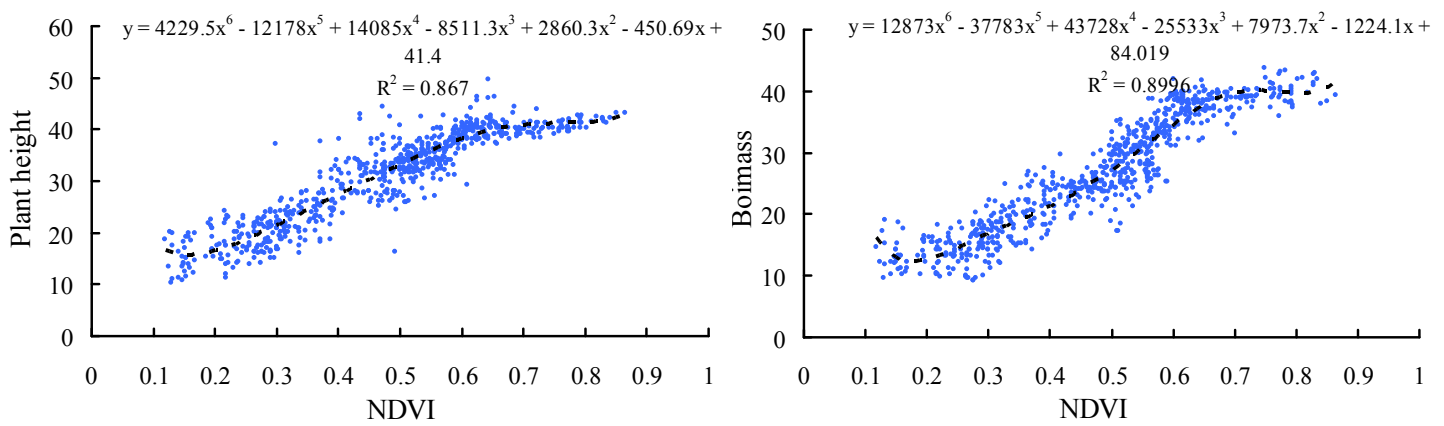

Figure 9. Prediction models of plant height and biomass by GS-NDVI

Four partitions can accurately express the group difference of corn growth status when using the K-mean. Although the $\mathrm{HC}$ algorithm can achieve better classification results, it has a large amount of computation. Distribution map of maize growth status difference was built by K-mean and 4 cluster numbers based on GS-NDVI (Fig. 10). 


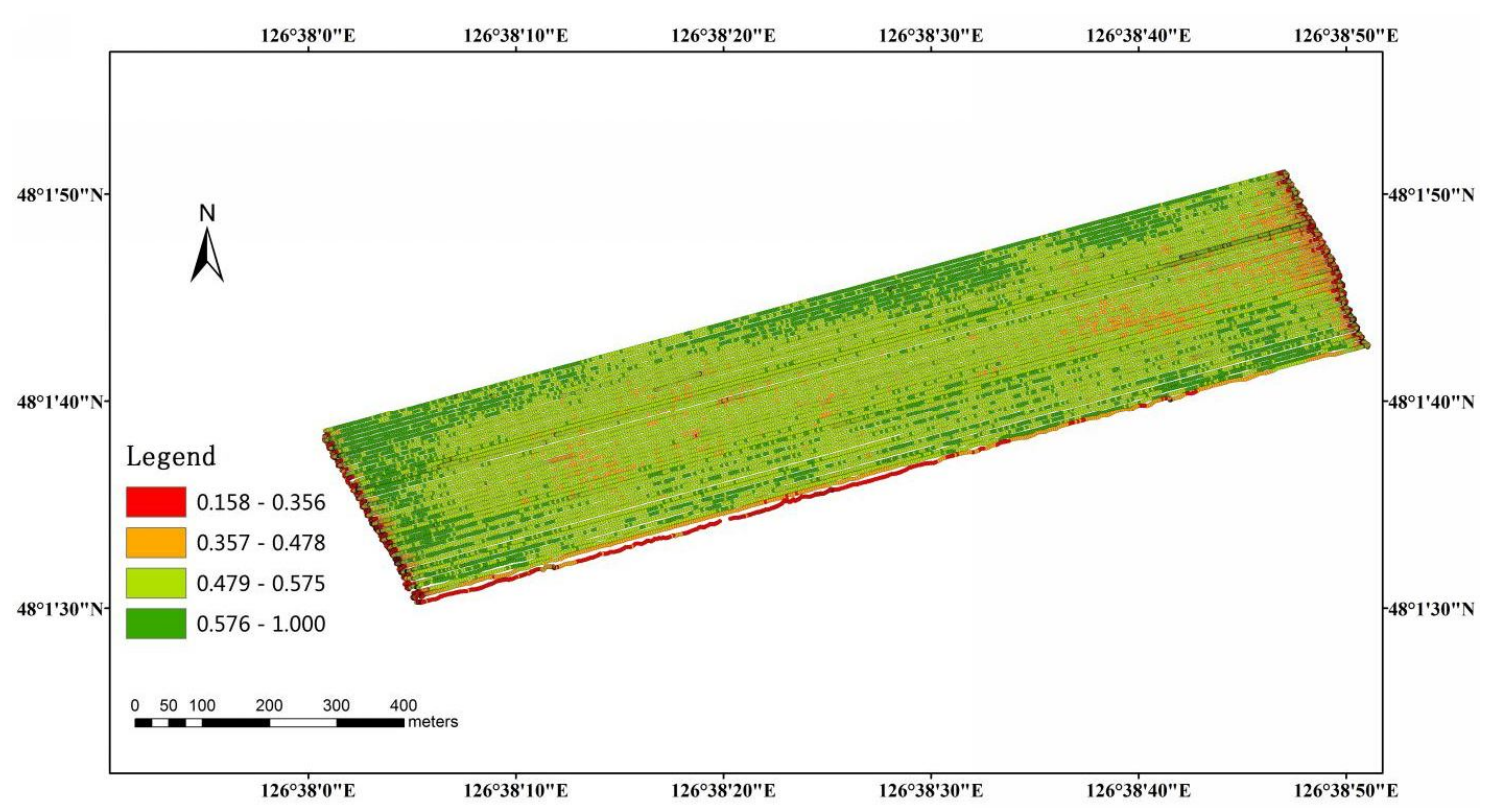

Figure 10. Maize growth map based on NDVI

\section{Discussion}

The definition of a specific location MANAGEMENT ZONING depends on spatial information that is stable or predictable over time. In this paper, the time series NDVI data were used to reflect the differences of maize growth. The overall variation of NDVI was $12 \%$, and the result is similar to that of previous research (Park and Moon, 2007; Zhang and Qiu, 2012).

Due to the differences in the working methods of the platform and the sensor, there are also differences in the NDVI data obtained in the crop canopy. Previous articles have discussed the differences in large-area plant canopy NDVI data acquired by different sensors. In this investigation, the trend of GS-NDVI and UAV-NDVI time series was compared. We found that there was no significant difference in the change trend of them on the whole plot, the accuracy of large-area GS-NDVI data was proved. Existing methods for comparing NDVI differences between different types of sensors were cumbersome. For example, compare the estimation errors of nitrogen content (Caturegli et al., 2016), the correlation between NDVI and crop yield (Duan et al., 2017). The method of this study directly compares NDVI data without the need to collect large-scale crop samples and test their chemical composition and the results were satisfactory.

$\mathrm{K}$-mean is more effective at expressing corn population differences than $\mathrm{Fcm}$. The results is different from other studies such as NDVI data clustering based on remote sensing images (Yang et al., 2012; Bandyopadhyay et al., 2007; Cammaran et al., 2011; Glass, 2007). The reason for this difference was that the NDVI data of the spectral image is more accurate (such as using image processing, texture features, etc. to remove outliers in the NDVI). In this investigation, we select the $\mathrm{m}$ value of Fcm concerning spectral image clustering, but the GS-NDVI collected in real time was greatly disturbed in the field, such as the reflectance of bare soil (Ghobadi et al., 2015). There are many abnormal data, which causes the selected $\mathrm{m}$ value of Fcm to be unsuitable for GSNDVI. 
The effectiveness of the number of partitions can be assessed by several criteria. The measure of variance reduction of the MANAGEMENT ZONING when compared to the within-field variance can be calculated (Sarangi, et al., 2015). Alternatively, the Variable Rate (VR) fertilization nutrients was applied based on a recommendation map derived from data associated with the MANAGEMENT ZONING. Then, a cost-benefit was analyzed based on the nutrients used (input) and yield obtained (output) to evaluate the effectiveness of the number of partitions (Halcro et al., 2013). The evaluation method SC used in this study is based on the same principle as the variance evaluation method. According to the existing research, the agronomic parameters of corn under different growth conditions have significant differences. Therefore, this paper uses agronomic parameters to evaluate the accuracy of the number of partitions and determine the optimal number of partitions. In conclusion, the research methods and evaluation methods used in this paper are feasible, and the result is effective for MANAGEMENT ZONING.

Plant height and biomass are important parameters for expressing corn growth status, and NDVI has a significant relationship with them. However, the GS-NDVI values were not accurate for plant height and biomass evaluation in the lower range $(0.118$ $0.293)$ and higher range (0.718-0.841). Other scholars have also obtained similar results when studying the correlation between NDVI and corn traits (Hansen et al., 2003; Yang et al., 2010, 2012). The reason for this result was due to excessive soil reflection from the corn canopy NDVI of small leaf area. Conversely, the NDVI high value appears saturated. At this time, NDVI cannot accurately estimate the corn trait.

According to K Lawton research (Lawton, 1946), the air permeability in the edge of the field was conducive to corn growth. The growth status of corn in the edge of lower left corner of experimental field was consistent with his conclusion. However, the growth status of corn in the edge of upper right corner of experimental field has poor growth. This problem may be due to the semi-sloping land, and upper right corner of the area with a low topographical position, the water stress affecting the growth of the corn. The corn in the lower edge of the field near the windbreak was poorly grown. According to the research of Reynolds et al. (2007), tree competition significantly reduced corn photosynthetic radiation (PAR), net assimilation (NA), and individual growth and yield. Relevant scholars have also researched the reasons for the difference in growth in other locations, but there is no unified answer at present.

\section{Conclusions}

The comparative method of NDVI time series trend was proposed to Indicate the effectiveness of the large-area NDVI of Greenseeker was worthy of recognition. At the same time, the optimal partition method of NDVI for management zone based on plant height and biomass of maize was discussed. The plant height evaluation accuracy results show that the contribution of cluster algorithm is greater than the number of partitions. The opposite result of biomass performance. When the number of partitions is 4 , a reasonable management partition map of NDVI was established based on Kmean.

In this paper, based on the NDVI data of Greenseeker, a reasonable management partition was established by clustering method, but data is processed offline. Therefore, the future research focuses on the development of online clustering methods. Develop a more intelligent and simple management partition real-time creation method. 
Acknowledgements. The authors would like to thank Edanz Editing and anonymous reviewers for their constructive comments and suggestions to improve the quality of the study. This work was partially supported by National Key R \& D project (2016YFD020060802).

\section{REFERENCES}

[1] Aavudai, A. (2016): Growing degree days-Ecosystem indicator for changing diurnal temperatures and their impact on corn growth stages in Kansas. - Ecological Indicators 61: 149-158.

[2] Abbasi, M. K., Tahir, M. M., Sadiq, A., Iqbal, M., Zafar, M. (2012): Yield and nitrogen use efficiency of rainfed maize response to splitting and nitrogen rates in Kashmir, Pakistan. - Agronomy Journal 104(2): 448-457.

[3] Allen, W. A., Gausman, H. W., Richardson, A. J. (1973): Theory of Leaf Reflectance Evaluated by Ray Tracing. - Appl. Opt 12(10): 2448-2453.

[4] Bandyopadhyay, S., Maulik, U., Mukhopadhyay, A. (2007): Multiobjective genetic clustering for pixel classification in remote sensing imagery. - IEEE Transactions on Geoscience and Remote Sensing 45(5): 1506-1511.

[5] Beckie, H. J., Moulin, A. P., Pennock, D. J. (1997): Strategies for variable rate nitrogen fertilization in hummocky terrain. - Canadian Journal of Soil Science 77(4): 589-595.

[6] Cai, W., Chen, S., Zhang, D. (2006): Fast and robust fuzzy c-means clustering algorithms incorporating local information for image segmentation. - Pattern Recognition 40(3): 825-838.

[7] Cammarano, D., Fitzgerald, G., Basso, B., O'Leary, G., Chen, D., Gracee, P., Fiorentinoc, C. (2011): Use of the canopy chlorophyl content index (CCCI) for remote estimation of wheat nitrogen content in rainfed environments. - Agronomy Journal 103(6): 1597-1603.

[8] Cao, Q., Cui, Z., Chen, X., Khosla, R., Dao, T. H., Miao, Y. (2012): Quantifying spatial variability of indigenous nitrogen supply for precision nitrogen management in small scale farming. - Precision Agriculture 13(1): 45-61.

[9] Caturegli, L., Corniglia, M., Gaetani, M., Grossi, N., Magni, S., Migliazzi, M., Angelini, L., Mazzoncini, M., Silvestri, N., Fontanelli, M., Raffaelli, M., Peruzzi, A., Volterrani, M. (2016): Unmanned aerial vehicle to estimate nitrogen status of turfgrasses. - Plos One 11(6).

[10] Chuang, K., Tzeng, H., Chen, S., Wu, J., Chen, T. (2006): Fuzzy c-means clustering with spatial information for image segmentation. - Computerized Medical Imaging and Graphics 30(1): 9-15.

[11] Cilia, C., Panigada, C., Rossini, M., Meroni, M., Busetto, L., Amaducci, S., Boschetti, M., Picchi, V., Colombo, R. (2014): Nitrogen status assessment for variable rate fertilization in maize through hyperspectral imagery. - Remote Sensing 6(7): 6549-6565.

[12] Colaço, A. F., Molin, J. P. (2017): Variable rate fertilization in citrus: a long term study. Precision Agriculture 18(2): 169-191.

[13] Condorelli, G. E., Maccaferril M., Newcomb, M., Andrade, P. -Sanchez, White, J. W., French, A. N., Sciara, G., Ward, R., Tuberosa, R. (2018): Comparative aerial and ground based high throughput phenotyping for the genetic dissection of NDVI as a proxy for drought adaptive traits in durum wheat. - Frontiers in Plant Science. https://doi.org/10.3389/fpls.2018.00893.

[14] Coque, M., Gallais, A. (2006): Genomic regions involved in response to grain yield selection at high and low nitrogen fertilization in maize. - Theoretical and Applied Genetic 112(7): 1205-1220.

[15] Cruppe, G., Edwards, J. T., Lollato, R. P. (2017): In-season canopy reflectance can aid fungicide and late-season nitrogen decisions on winter wheat. - Agronomy Journal 109(5): 2072-2086. 
[16] Di Gennaro, S. F., Rizza, F., Badeck, F. W., Berton, A., Delbono, S., Gioli, B., Toscano, P., Zaldei, A., Mates, A. (2017): UAV-based high-throughput phenotyping to discriminate barley vigour with visible and near-infrared vegetation indice. International Journal of Remote Sensing 39(15-16): 5330-5344.

[17] Duan, T., Chapman, S. C., Guo, Y., Zheng, B. (2017): Dynamic monitoring of NDVI in wheat agronomy and breeding trials using an unmanned aerial vehicle. - Field Crops Research 15(8): 71-80.

[18] Fleming, K. L., Westfall, D. G., Wiens, D. W., Brodahl, M. C. (2000): Evaluating farmer defined management zone maps for variable rate fertilizer application. - Precision Agriculture 2(2): 201-215.

[19] Fu, W., Tunney, H., Zhang, C. (2010): Spatial variation of soil nutrients in a dairy farm and its implications for site-specific fertilizer application. - Soil and Tillage Research 106(2): 185-193.

[20] Gérard, B., Buerkert, A., Hiernaux, P., Marschner, H. (1997): Non-destructive measurement of plant growth and nitrogen status of pearl millet with low-altitude aerial photography. - Plant Nutrition for Sustainable Food Production and Environment 373378.

[21] Ghobadi, Y., Pradhan, B., Shafri, H. Z. M., Kabiri, K. (2015): Assessment of spatial relationship between land surface temperature and landuse/cover retrieval from multitemporal remote sensing data in South Karkheh Sub-basin, Iran. Arabian. - Journal of Geosciences 8(1): 525-537.

[22] Glass, A. D. M. (2003): Nitrogen use efficiency of crop plants: physiological constraints upon nitrogen absorption. - Critical Reviews in Plant Science 24: 453-470.

[23] Halcro, G., Corstanje, R., Mouazen, A. M. (2013): Site-specific land management of cereal crops based on management zone delineation by proximal soil sensing. - Precision Agriculture 13: 475-481.

[24] Hansen, P. M., Schjoerring, J. K. (2003): Reflectance measurement of canopy biomass and nitrogen status in wheat crops using normalized difference vegetation indices and partial least squares regression. - Remote Sensing of Environment 86(4): 542-553.

[25] Hassan, M. A., Yang, M., Rasheed, A., Yang, G., Reynolds, M., Xia, X., Xiao, Y., He, Z. (2018): A rapid monitoring of NDVI across the wheat growth cycle for grain yield prediction using a multi-spectral UAV platform. - Plant Science (2): 152-158.

[26] Herbst, M., Prolingheuer, N., Graf, A., Huisman, J. A., Weihermüller, L., Vanderborght, J. (2009): Characterization and understanding of bare soil respiration spatial variability at plot scale. - Vadose Zone J 8(3): 762-771.

[27] Huang, Z. (1998): Extensions to the k-means algorithm for clustering large data sets with categorical values. - Data Mining and Knowledge Discovery 2(3): 283-304.

[28] Ingerstad, T. (1982): Relative addition rate and external concentration; Driving variables used in plant nutrition research. - Cell \& Environment 5(6): 443-453.

[29] Jia, L., Buerkert, A., Chen, X., Roemheld, V., Zhang, F. (2004): Low-altitude aerial photography for optimum $\mathrm{N}$ fertilization of winter wheat on the North China Plain. Field Crops Research 89(2-3): 389-395.

[30] Jin, S., Zhou, F. (2018): Zero growth of chemical fertilizer and pesticide use: china's objectives, progress and challenges. - Journal of Resources and Ecology 9(sp1): 50-58.

[31] John, R., Dalling, J. W., Harms, K. E., Yavitt, J. B., Stallard, R. F., Mirabello, M., Hubbell, S. P., Valencia, R., Navarrete, H., Vallejo, M., Foster, R. B. (2007): Soil nutrients influence spatial distributions of tropical tree species. - PNAS 104(3): 864-869.

[32] Lawton, K. (1946): The Influence of soil aeration on the growth and absorption of nutrients by corn plants. - Soil Science Society of America Journal, 263-268.

[33] McKinion, J. M., Jenkins, J. N., Willers, J. L., Zumanis, A. (2009): Spatially variable insecticide applications for early season control of cotton insect pests. - Computers and Electronics in Agriculture 67(1-2): 71-79. 
[34] Mulla, D. J., Bhatti, A. U., Hammond, M. W., Benson, J. A. (1992): A comparison of winter wheat yield and quality under uniform versus spatially variable fertilizer. Agriculture, Ecosystems \& Environment 38(4): 301-311.

[35] Omran, M., Engelbrecht, A. P., Salman, A. (2005): Particle swarm optimization method for image clustering. - International Journal of Pattern Recognition and Artificial Intelligence 19(3): 297-321.

[36] Orteg, R. A., Santibáñez, O. A. (2007): Determination of management zones in corn (Zea mays, L.) based on soil fertility. - Computers and Electronics in Agriculture 88(1): 49-59.

[37] Park, S., Moon, W. M. (2007): Unsupervised classification of scattering mechanisms in polarimetric SAR data using fuzzy fuzzy logic in entropy and alpha plane. - IEEE Transactions on Geoscience and Remote 45(8): 2652-2664.

[38] Rajkovich, S., Enders, A., Hanley, K., Hyland, C., Zimmerman, A. R., Lehmann, J. (2012): Corn growth and nitrogen nutrition after additions of biochars with varying properties to a temperate soil. - Biology and Fertility of Soils 48(3): 271-284.

[39] Ramchandran, D., Johnston, D. B., Tumbleson, M. E., Rausch, K. D., Singh, V. (2015): Seasonal variability in ethanol concentrations from a dry grind fermentation operation associated with incoming corn variability. - Industrial Crops and Products 64: 155-160.

[40] Ramirez, M. B., Allen, P. B., Freeland, R. S., Wilkerson, J. B. (2017): Cotton canopy NDVI: reducing the ground exposure effect. - Transactions of the ASABE 60(2): 293301.

[41] Raun, W. R., Solie, J. B., Johnson, G. V., Stone, M. L., Mullen, R. W., Freeman, K. W., Thomason, W. E., Lukina, E. V. (2002): Improving nitrogen use efficiency in cereal grain production with optical sensing and variable rate application. - Agronomy Journal 94(4): 815-827.

[42] Ren, J., Chen, Z., Zhou, Q., Tang, H. (2008): Regional yield estimation for winter wheat with MODIS-NDVI data in Shandong, China. - International Journal of Applied Earth Observation and Geoinformation 10(4): 403-413.

[43] Reynolds, P. E., Simpson, J. A., Thevathasan, N. V., Gordon, A. M. (2007): Effects of tree competition on corn and soybean photosynthesis, growth, and yield in a temperate tree-based agroforestry intercropping system in southern Ontario, Canada. - Ecological Engineering, 29(4): 362-371.

[44] Sangalli, L. M., Secchi, P., Vantini, S., Vitelli, V. (2010): K-mean alignment for curve clustering. - Computational Statistics \& Data Analysis 54(5): 1219-1233.

[45] Sarangi, S. K., Maji, B., Singh, S., Sharma, D. K., Burman, D., Mandal, S., Singh, U. S., Ismail, A. M., Haefele, S. M (2015): Using improved variety and management enhances rice productivity in stagnant flood-affected tropical coastal zones. - F. Crop. Res 190: 7081.

[46] Schepers, A. R., Shanahan, J. F., Liebig, M. A., Schepers, J. S., Johnson, S. H., Luchiaric, A. (2004): Appropriateness of management zones for characterizing spatial variability of soil properties and irrigated corn yields across years. - Agronomy Journal 9(1): 195-203.

[47] Sun, S. K., Lu, Y. J., Gao, H., Jiang, T. T., Du, X. Y., Shen, T. X., Wu, P. T., Wang, Y. B. (2018): Impacts of food wastage on water resources and environment in China. Journal of Cleaner Production 185: 732-739.

[48] Wang, J., Fu, B., Qiu, Y., Chen, L. (2001): Soil nutrients in relation to land use and landscape position in the semi-arid small catchment on the loess plateau in China. Journal of Arid Environments 48(4): 537-550.

[49] Yang, F., Sun, J., Fang, H., Yao, Z., Zhang, J., Zhu, Y., Kaishan, S. et al. (2012): Comparison of different methods for corn LAI estimation over northeastern China. International Journal of Applied Earth Observation and Geoinformation 18: 462-471.

[50] Yang, J., Parikh, D., Batra, D. (2016): Joint unsupervised learning of deep representations and image clusters. - The IEEE Conference on Computer Vision and Pattern Recognition 5147-5156. DOI: 10.1109/CVPR.2016.556. 
[51] Yang, W., Li, M., Sigrimis (2010): Nick estimating nitrogen content of cucumber leaves based on nIR spectroscopy. - Sensor Letters 8(1): 145-150.

[52] Yang, Y., Fulin, W., Jie, Z. (2009): Intelligent fertilization decision support system based on knowledge model and WebGIS: Decision for fertilization. - Computer Science and Information Technology 8(11): 232-235.

[53] Zhang, C., Qiu, F. (2012): Hyperspectral image classification using an unsupervised neuro-fuzzy system. - Journal of Applied Remote Sensing 6(1): 112-121.

[54] Zhang, X., Shi, L., Jia, X., Seielstad, G., Helgason, C. (2010): Zone mapping application for precision-farming: a decision support tool for variable rate application. - Precision Agriculture 11(2): 103-114.

[55] Zhou, K., Sui, Y., Xu, X., Zhang, J., Chen, Y., Hou, M., Jiao, X. (2018): The effects of biochar addition on phosphorus transfer and water utilization efficiency in a vegetable field in Northeast China. - Agricultural Water Management 210: 324-329. 